\title{
A Fuzzy Conceptual Design Selection Model Considering Conflict Resolution
}

\author{
A. Sarfaraz and K. Jenab
}

\begin{abstract}
Selecting a design at the conceptual design stage in product development can be complex and frustrating due to imprecise and uncertain product requirements. For many companies, the conceptual design stage is crucial to their product's success. For example, making a bad decision can lead to costs associated with product recall, redesign, and remanufacture. These unexpected expenses not only could result in profit loss but also jeopardize a successful commercialization of the product. Therefore, the level of success of a product is significantly dependent on the early stage of product development. Managers need robust decision-making tools for valuing potential new product investments in order to justify their development strategy and to allow them to screen out new designs that stand little chance of success at an early stage. However, limitations, such as uncertainty and inability to provide the information on the compatibility between design concepts, remain as challenges for the concept selection method. Therefore, this study proposes a structured conceptual design selection model based on fuzzy analytic hierarchy process (FAHP) and fuzzy conflict resolution to express the comparative judgments of decision-makers. Also, we perform a comparative analysis between AHP and FAHP results by applying our model to hospital bed designs. This study proves that although both methods are good, FAHP is more robust because of eliminating inconsistencies resulted from personal feelings or judgments.
\end{abstract}

Index Terms-Conceptual design stage, AHP, fuzzy AHP, ergonomic design, design for reliability, conflict resolution.

\section{INTRODUCTION}

In today's world, there are major changes in the commercial market due to advances in technology. Companies are forced to develop new products for current markets, especially in technology-driven or high-tech markets. Therefore, the need for decision-making tools which determines the best option is essential. Organizations are continually challenged to effectively evaluate products involving multiple criteria to ascertain the most suitable alternative for a chance of creating profitable product. A product most important stage is the design stage. The design stage is broken down into multiple criteria and sub-criteria called "Design for" based on customer demands and available technology. The critical phase in the design stage is weighing which criteria are of most importance to the customer. Ideally, a product can be designed to satisfy all customer needs, but that can result in an overly priced

Manuscript received October 20, 2011; revised November 23, 2011.

A. Sarfaraz is with the Department of Manufacturing System Engineering and Management, California State University-Northridge, USA (e-mail: sarfaraz@csun.edu).

K. Jenab is Education Chair at Society of Reliability Engineering-Ottawa, Canada (e-mail: jenab@ieee.org). product. Unless the consumers are not concerned with the products' price, the product will have no chance to be marketable. Wang et al., (2002) studied the domain of collaborative conceptual design based in technologies in order to understand the needs for conceptual design engineering and to clarify the current conceptual design practice [17]. Kurakawa (2004) proposed a model based the viewpoint of the designer's cognition. This model was developed based on scenario-driven conceptual design information which is a fundamental part of practical design support tools [9]. Chong et al., (2009) proposed a heuristic method for applications on conceptual design in order to guide designers in the investigation of design concepts problems [4]. Kim \& Xirouchakis (2010) proposed a decision support system for the design concept filtering and selection stages [7]. Avigad et al., (2011) developed a fuzzy computational tool based on supply chain that helps designers in selecting an engineering concept [1]. Nagel et al., (2011) reported a functional modeling for product design where customer needs are translated into a representation of elementary operations defining a desired goal [12].

Also, a tool that can be used to find the best conceptual design option is Analytic Hierarchy Process (AHP). In [13] and [14, The Analytical Hierarchy Process (AHP) model was designed by Saaty. It is especially suitable for complex decisions which involve the comparison of decision elements which are difficult to quantify [10] and [11]. One of the main advantages of this method is the relative ease with which it handles multiple criteria. In addition to this, AHP is easier to understand and it can effectively handle both qualitative and quantitative data [2]. However, limitations, such as uncertainty in [18] and inability to provide the information on the compatibility between design concepts in [8], remain as challenges for the concept selection method. To improve the AHP method and to determine the relative weight of criteria for risk assessment, this study proposes a structure conceptual design selection model based on the use of fuzzy analytic hierarchy process (FAHP) and triangular fuzzy numbers. This approach expresses the comparative judgments of decision-makers [6]. It is used to reduce multiple design alternatives by eliminating those for which their overall weights are smaller and considered less important.

FAHP is a powerful and flexible multi-criteria decision-making tool for dealing with complex problems. It deals with both qualitative and quantitative aspects of a problem and eliminates the human preference model and its uncertainties when decision-makers are reluctant or unable to assign exact numerical values to the comparison judgments. The evaluation model can help make effective decisions without the uncertainty and vagueness in the evaluation 
process. Also, FAHP is widely used to evaluate numerous problems organizations are face with. Below are some decision making problems, FAHP has been applied to: Evaluating energy resources; Evaluating marketing strategies; Evaluating budget allocation; Selecting assembly line selection; Selecting the appropriate design concept; Selecting a technology source; Selecting the adequate petroleum pipeline industry; Aid in traffic planning; Selecting the appropriate casting process.

In this paper, we develop a structured conceptual design selection model based on FAHP and multiple experts' conflict resolution to find the best design for a hospital bed design. Introducing seven different hospital bed designs, we use AHP and FAHP to evaluate which design is the most suitable design. Finally, we present how the use of fuzzy conflict resolution and FAHP handles uncertainty and the lack of crisp information on the compatibility between designs.

\section{INTRODUCTION TO FUZZY AHP}

In comparison to the traditional AHP which deals with vagueness and subjective decisions, Fuzzy AHP has been improved by eliminating these unwanted factors in the pair-wise comparison stage. In the decision-making environment of the AHP, the input information and relations between criteria and alternatives are uncertain and imprecise. Instead of dealing with a single crisp value, Fuzzy AHP uses a range of values to incorporate the decision maker's uncertainties. From this range, decision makers can select the value that reflects his or her confidence and also can specify attitudes like optimistic, pessimistic or moderate [5] and [19]. Optimistic attitude is represented by the highest value of range, moderate attitude is represented by the middle value of the range and pessimistic attitude is represented by the lowest value of the range.

\section{A. Fuzzy Numbers}

In the fuzzy set terminology, the ratio supplied by the decision maker is a fuzzy number. The concept of fuzzy set was introduced in the mid-1960s to overcome the limitation of the conventional crisp sets, where the relation of a data and a set is described by either "in" or "out" [21]. Fuzzy numbers are used to represent uncertain values. A fuzzy number does not necessarily refer to one value but rather a connected set, range or membership. Fuzzy numbers are utilized to capture vagueness.

\section{B. Triangular Fuzzy Numbers}

In norm, a triangular fuzzy number is used to represent the decision maker's assessment on alternatives with respect to each criterion. Triangular fuzzy numbers are similar to fuzzy numbers; the difference is that they capture a range of numbers within a triangular boundary. The boundaries are set by parameters $l, m$, and $u$. Value $l$ being the smallest possible value, $m$ the most promising value and $u$ being the largest possible value. This can be expresses using the following equation [3]:

$$
\mu_{M}(x)= \begin{cases}\frac{x}{m-l}-\frac{l}{m-l}, & x \in[l, m] \\ \frac{x}{m-u}-\frac{u}{m-u}, & x \in[m, u] \\ 0, & \text { otherwise }\end{cases}
$$

Triangular fuzzy numbers are easy to use and apply. If a value falls within the triangular range, that value is said to have a membership. A membership can be described as being a part of or having relevance. This concept helps to eliminate the uncertainty that's created through personal judgments in the pair-wise comparison stage.

\section{Applying Fuzzy Numbers in a Pair-Wise Comparison Scale}

It is difficult to map qualitative preferences to point estimates, hence a degree of uncertainty will be associated with some or all pair-wise comparison values in an FAHP problem [20]. By using triangular fuzzy numbers, via the pair-wise comparisons made, the fuzzy comparison matrix $A=\left(a_{i j}\right)_{n \times m}$ [15].The methodology is similar to the classic AHP. Matrix $A=\left(a_{i j}\right)_{n \times m}$ is created, given that $a_{i j}=\left(l_{i j}, m_{i j}, u_{i j}\right)$ and the pair-wise comparison scale can be represented by $a_{i j}$ ${ }^{-1}=\left(1 / u_{i j}, 1 / m_{i j}, 1 / l_{i j}\right)$.

\section{Applying Fuzzy AHP Algorithm}

In this study, extent analysis method is utilized to elaborate a fuzzy synthetic extent. Extent analysis was originally introduced by [3]. The extent analysis states the following: Let $X\left\{x_{1}, x_{2}, x_{3}, \ldots \ldots ., x_{n}\right\}=$ a design concept set, and $G$ $\left\{g_{1}, g_{2}, g_{,} \ldots \ldots, g_{n}\right\}=$ be a goal set. According to the method of Chang's extent analysis [3], each design concept is taken and extent analysis for each goal performed, respectively. Therefore, $m$ extent analysis values for each design concept can be denoted by $M_{g i}^{j}$ for $i=1,2, \ldots, n$; $j=1,2, \ldots, m$ which are triangular fuzzy numbers. Now after clarifying the meaning of the signs and variables, Chang's extent analysis [3] can be described in the following steps:

Step a: The value of fuzzy synthetic extent with respect to the $i$ th design concept is defined as

$$
S_{i}=\sum_{j=1}^{m} M_{g i}^{j} \Theta\left[\sum_{i=1}^{n} \sum_{j=1}^{m} M_{g i}^{j}\right]^{-1}
$$

Step $b$ : To obtain the degree of possibility two triangular fuzzy numbers $M_{1}=\left(l_{1}, m_{1}, u 1\right)$ and $M_{2}=\left(l_{2}, m_{2}, u_{2}\right)$ are declared. The degree of possibility states that $M_{2}=\left(l_{2}, m_{2}, u 2\right)$ $\geq M_{1}=\left(l_{1}, m 1, u 1\right)$ defined as

$$
\mathrm{V}\left(\mathrm{M}_{1} \geq \mathrm{M}_{2}\right)=\sup _{x \geq y}\left[\min \left(\mu_{\mathrm{M}_{1}}(\mathrm{x}), \mu_{\mathrm{M}_{2}}(\mathrm{y})\right)\right]
$$

and can be equivalently expressed as follows (Chang, 1992):

$$
\begin{gathered}
\mathrm{V}\left(\mathrm{M}_{2} \geq \mathrm{M}_{1}\right)=\operatorname{hgt}\left(\mathrm{M}_{1} \cap \mathrm{M}_{2}\right)=\mu_{\mathrm{M}_{1}}(d) \\
\frac{l_{1}-u_{2}}{\left(m_{2}-u_{2}\right)-\left(m_{1}-l_{1}\right)}
\end{gathered}
$$

Step c: The degree of possibility for a convex fuzzy number to be greater than $k$ convex fuzzy numbers $M i(i=1,2$, k) can be defined by

$$
\begin{gathered}
V\left(M \geq M_{1}, M_{2}, \ldots ., M \mathrm{k}\right)=V\left[\left(M \geq M_{1}\right) \text { and } \ldots \text { and }(M \geq\right. \\
M \mathrm{k})]=\min V(M \geq M i)], \quad i=1,2,3, \ldots, k .
\end{gathered}
$$

Assuming that

$$
\mathrm{d}(\mathrm{Ai})=\min \mathrm{V}(\mathrm{Si} \geq \mathrm{Sk}), \text { for } k=1,2, \ldots ., n ; k \neq l .
$$

Then, the weight vector is given by

$$
W^{\prime}=\left(d^{\prime}\left(A_{1}\right), d^{\prime}\left(A_{2}\right), \ldots \ldots, d^{\prime}\left(A_{n}\right)\right)^{T}
$$

where $A_{i}(i=1,2, \ldots n)=$ are $\mathrm{n}$ elements. 
By normalizing, the normalized weight vectors are obtained:

$$
W=\left(d\left(A_{1}\right), d\left(A_{2}\right), \ldots \ldots, d\left(A_{n}\right)\right)^{T}
$$

\section{Fuzzy Conceptual Design Selection Model}

This study report a structured conceptual design selection model based on "Design for" concept called $D f X$. The model incorporates all design experts' evaluations into a final decision, without having to elicit their utility functions on subjective and objective criteria such as Design for Manufacturing Cost $(D f M / C)$, Design for Ergonomic $(D f E)$, Design for Performance/Reliability $(D f P / R)$, Design for Safety $(D f S)$, Design for Maintenance $(D f M)$, etc. Then, $S u b-D f X$ for each $D f X$ are determined in order to form a hierarchical structure used for a series of pair-wise comparison judgments among design alternatives as shown in Fig. 1.

Step 1: Determine $D f X$

Step 1-1: Using linguistic variables (A: Absolute, V: Very strong, F: Fairly strong, W: Weak, E: Equal), obtain the $\mathrm{k}^{\text {th }}$ expert's opinion $\left(e_{i j}^{k}\right)$ for pairwise comparison between

$$
\begin{aligned}
& e_{i j}^{k}=\left\{D f X_{i} \stackrel{e_{k}}{\longrightarrow} D f X_{j} \mid i=1,2, \ldots, n-1 ; j>i,\right. \\
& k=1,2, \ldots, K\}
\end{aligned}
$$

For example, if $e_{i j}^{k}$ is determined ' $V$ ' by expert $k$, then $e_{j i}^{k}$ is ' $1 / V$ '.

Step 1-2: The experts' opinions differ substantially because the experts do not often agree on the level of the $D f X$ s. Therefore, we have to resolve the conflict by using maximum aggregation function

$$
D f X_{\text {agg }}^{i \longrightarrow j}=\max \left(e_{i j}^{k} \mid k=1,2, \ldots K, \forall i, j, i>j\right) \text {. }
$$

Step 1-3: Calculate the aggregated linguistic variable for The Sub-DfXs by using minimum aggregation function

$$
\begin{aligned}
& S u b-D f X_{a g g}^{i \longrightarrow j}=\min \left(e_{s u b-i j}^{k} \mid k=1,2, \ldots K,\right. \\
& \forall i, j, i>j)
\end{aligned}
$$

Step 1-4: Using Table I [16], convert the linguistic variables to triangular fuzzy number

TABLE I: EQUIVALENT OF LINGUISTIC VARIABLE TO TRIANGULAR FuZZY

\begin{tabular}{cc}
\multicolumn{2}{c}{ NUMBER } \\
\hline Linguistic variable & TFN \\
\hline Absolute & $(7 / 2,4,9 / 2)$ \\
Very strong & $(5 / 2,3,7 / 2)$ \\
Fairly strong & $(3 / 2,2,5 / 2)$ \\
Weak & $(2 / 3,1,3 / 2)$ \\
Equal & $(1,1,1)$ \\
\hline
\end{tabular}

Step 2: Performing Step (a), calculate weights of $D f X$. The pairwise comparison matrix of $D f X$ is formed by aggregating the design expert's preferences.

Step 3: Performing Steps (b) \& (c), calculate weights of design concept with respect to each $D f X$.

Step 4: Having the weights of each alternative with respect of each $D f X$, calculate final raking number by adding up the weight per design concept multiplied by the corresponding DfXs.

Step 5: Rank the design concepts with respect to their final

ranking number.

To demonstrate the application of the model and perform comparative analysis, we execute this model with crisp and fuzzy information for the conceptual design of the hospital bed.

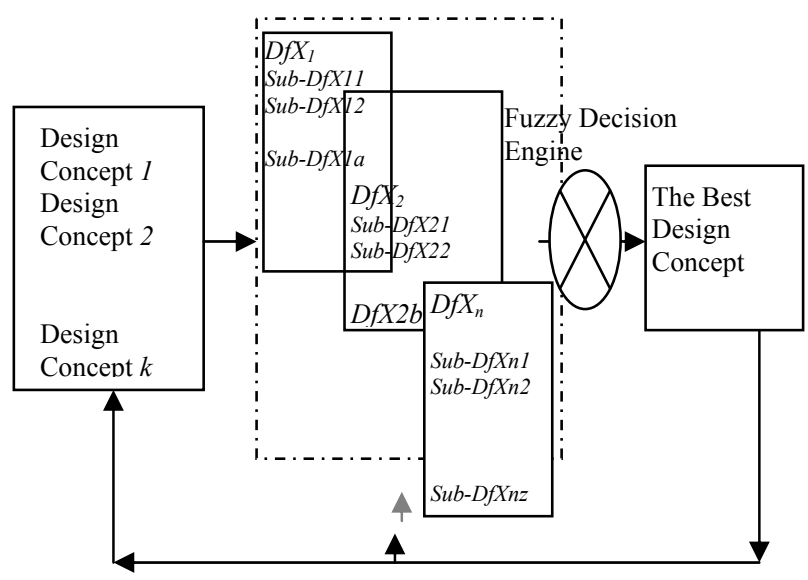

Fig. 1. Structured conceptual design selection process.

\section{SOME COMMON MistaKes}

In this example, we consider seven conceptual designs for the hospital beds as shown in Fig. 2. After brainstorming, DfX are: Reliability (R), Safety (S), Manufacturing cost (C), Ergonomic (E), and Maintenance (M). Also, we define Sub-DfX with lesser significance branched down from each of the DfX's. For example, the Sub-DfXs for performance are: easy to transfer (ETT), easy to operate (ETO), easy to store (ETS), light weight (LW) and strong frame (SF). Fig. 3 presents the structured conceptual design selection process for the hospital bed.

Subsequent to creating the hierarchy stature, a pair-wise comparison is performed (See Table III). Also, Table VII shows that performance has the highest intensity over cost and maintenance. This means that performance is of greater relevance to the conceptual design in question than cost and maintenance.

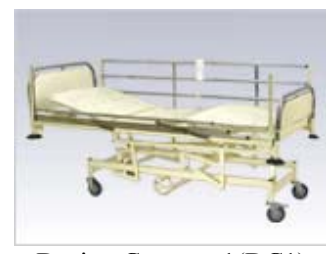

Design Concept 1(DC1)

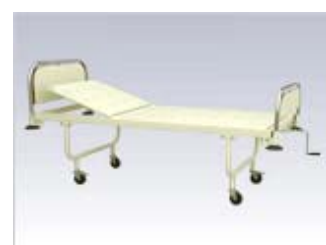

Design Concept 3(DC3)

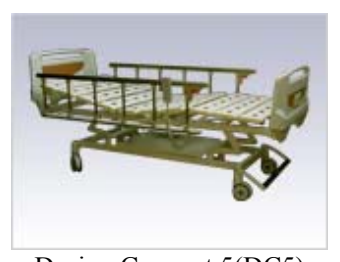

Design Concept 5(DC5)
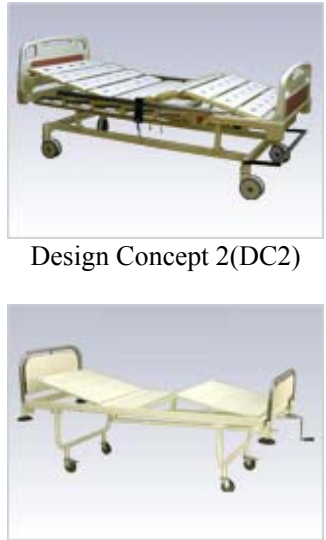

Design Concept 4(DC4)

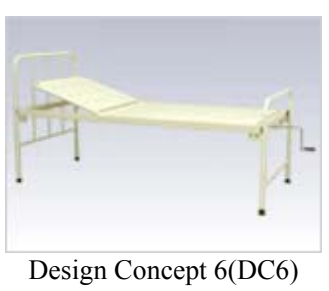




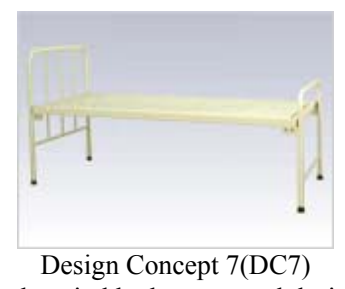

Fig. 2. The hospital bed conceptual design options.

Now, we execute the model with crisp and fuzzy information to show how the use of fuzzy AHP can overcome the limitations such as uncertainty and inability to provide the information on the compatibility between design concepts.

\section{A. Finding the Best Hospital Bed Design Concept with Crisp Information}

To perform step 2, the pairwise comparison matrix of DfX is formed based on the design expert's preference (See Table II).

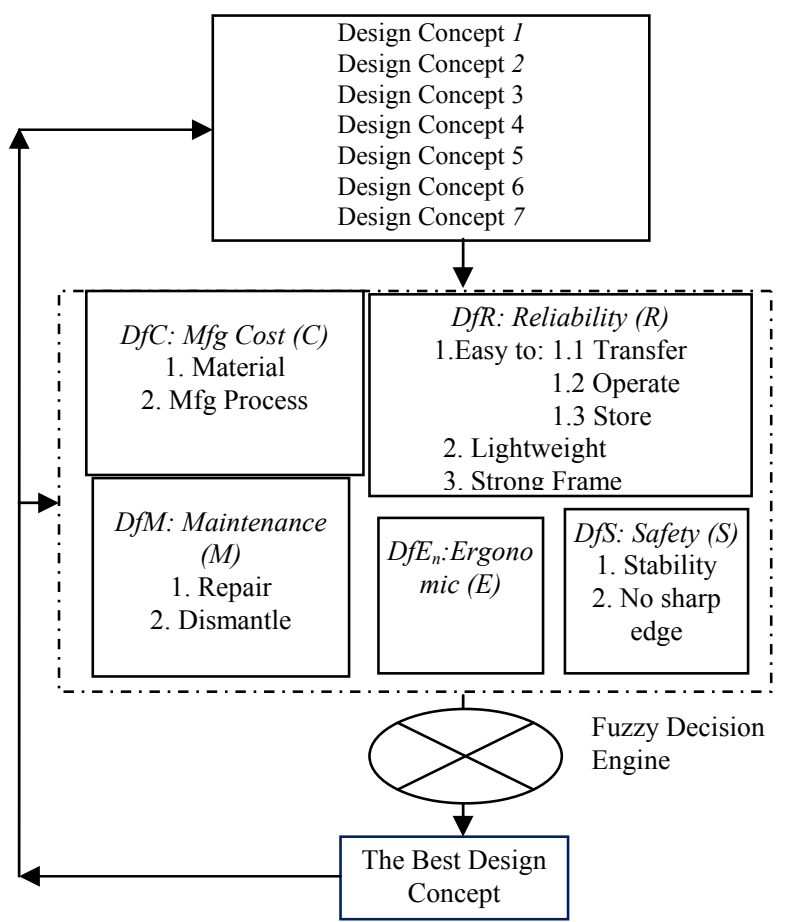

Fig. 3. Structured conceptual design selection process for hospital beds.

TABLE II: PAIR-WISE COMPARISON OF CRITERIA WITH RESPECT TO OVERALL GOAL

\begin{tabular}{lccccc}
\hline \multicolumn{1}{c}{$\boldsymbol{D} \boldsymbol{f} \boldsymbol{X}$} & $\mathbf{R}$ & $\mathbf{S}$ & $\mathbf{C}$ & $\mathbf{E}$ & $\mathbf{M}$ \\
\hline Reliability (R) & 1 & 3 & $a=5$ & 3 & 5 \\
Safety (S) & $1 / 3$ & 1 & 3 & 1 & 3 \\
Manufacturing Cost (C) & $1 / 5$ & $1 / 3$ & 1 & $1 / 3$ & 3 \\
Ergonomic (E) & $1 / 3$ & 1 & 3 & 1 & 3 \\
Maintenance (M) & $1 / 5$ & $1 / 3$ & $1 / 3$ & $1 / 3$ & 1 \\
\hline \multicolumn{1}{c}{ Total } & $\mathbf{2 . 0 6 7}$ & $\mathbf{5 . 6 6 7}$ & $\mathbf{1 0 . 3 3 3}$ & $\mathbf{6 . 3 3 3}$ & $\mathbf{1 5 . 0}$ \\
\hline
\end{tabular}

Following the pair-wise comparison are calculations performed to compute the total priority vector (weight) of each of the DfX's and Sub-DfX's. We perform the pair-wise comparison and calculate the Priority Vectors along with the Consistency Ratios using Excel.

- Table II shows Priority Vector (PV) and Consistency Ratio (CR) of the DfXs. The consistency ratio is designed in such a way that shows a reasonable level of consistency in the pair-wise comparisons if $\mathrm{CR}<0.10$

- Table III presents Priority Vector (PV) and Consistency
Ratio (CR) of the Sub-DfXs. The consistency ratio is designed in such a way that shows a reasonable level of consistency in the pair-wise comparisons if $\mathrm{CR}<0.10$

The mathematical calculations performed in Tables III and IV provide a reasonable level of confidence, meaning the judgments performed during the pair-wise comparisons were consistent and are therefore reliable. Next, the overall priority vector for the seven design alternatives is calculated. Table $\mathrm{V}$ illustrates the priority vectors for the $D f X, S u b-D f X s$ and the design concepts alternatives.

Note that the priority vectors for the alternatives are provided in Table VI. The following is an example on how to calculate the priority vector for DC-2 based on priority vectors for $D f X s, S u b-D f X s$ and the design concept DC2 in Table IV:

$0.104(0.415)+0.081(0.251)+0.074(0.056)+0.290(0.127)+$ $0.061(0.151)=0.114$.

Last step in calculating the overall priority vector is performing the same procedure and multiplying the results in Table VI. Results are shown in Table VII.

TABLE III: PRIORITY VECTOR AND CONSISTENCY TEST FOR DFXS Synthesized Matrix

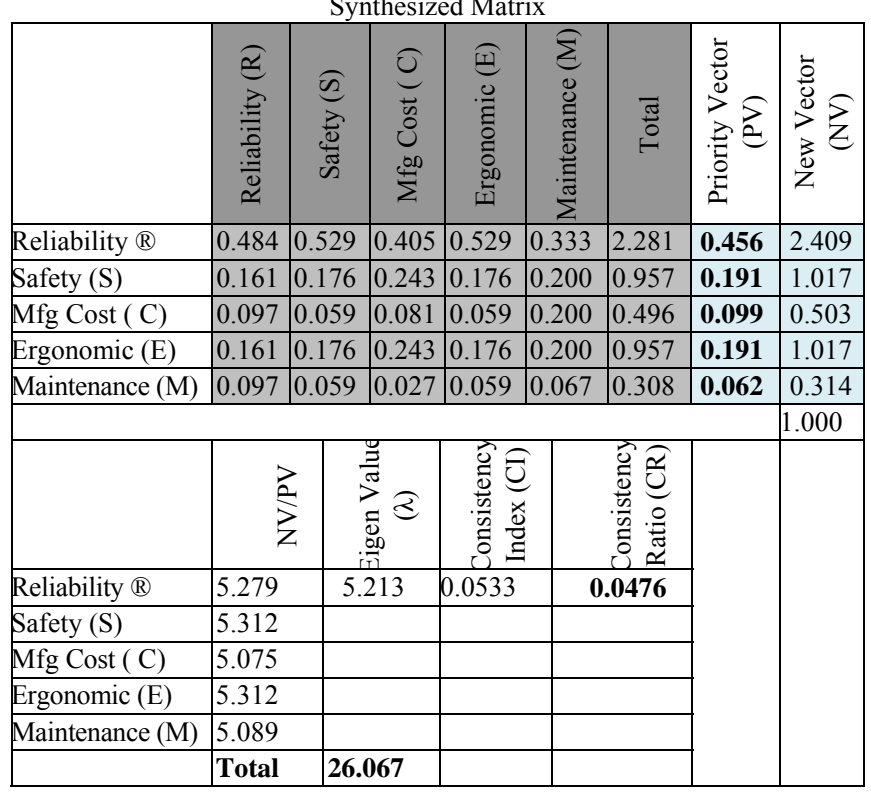

TABLE IV: PRIORITY VECTOR AND CONSISTENCY TEST FOR THE SUB-DFXS Synthesized Matrix

\begin{tabular}{|c|c|c|c|c|c|c|c|c|}
\hline & ETT & ETU & ETS & LW & SF & Total & 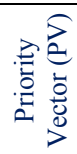 & $\begin{array}{l}0_{0}^{0} \\
\stackrel{0}{0} \\
3 \\
0 \\
z\end{array}$ \\
\hline ETT & 0.455 & 0.600 & 0.294 & 0.360 & 0.366 & 2.075 & 0.415 & 2.283 \\
\hline ETU & 0.152 & 0.200 & \begin{tabular}{|l|}
0.176 \\
\end{tabular} & 0.360 & 0.366 & 1.254 & 0.251 & 1.392 \\
\hline ETS & 0.091 & 0.067 & 0.059 & 0.040 & 0.024 & 0.281 & 0.056 & 0.295 \\
\hline LW & 0.152 & 0.067 & 0.176 & 0.120 & 0.122 & 0.637 & 0.127 & 0.669 \\
\hline \multirow[t]{3}{*}{ SF } & 0.152 & 0.067 & \begin{tabular}{|l|}
0.294 \\
\end{tabular} & 0.120 & 0.122 & 0.754 & 0.151 & 0.781 \\
\hline & & & & & & & 1.000 & Total \\
\hline & $\frac{z}{z}$ & 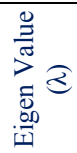 & 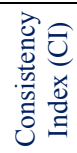 & 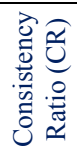 & $\frac{\text { B }}{\text { z }}$ & 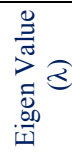 & & \\
\hline ETT & 5.501 & 5.348 & 0.087 & 0.078 & & & & \\
\hline ETU & 5.551 & & & & & & & \\
\hline ETS & 5.259 & & & & & & & \\
\hline LW & 5.251 & & & & & & & \\
\hline SF & 5.176 & & & & & & & \\
\hline Total & \begin{tabular}{|l|}
26.739 \\
\end{tabular} & & & & & & & \\
\hline
\end{tabular}




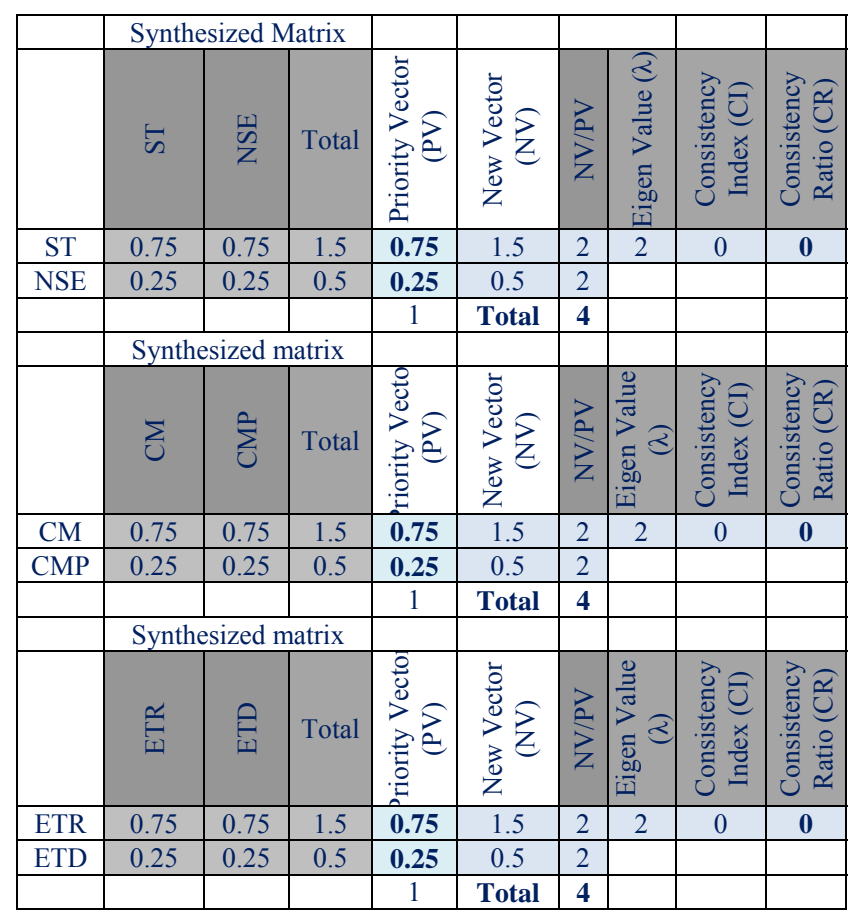

\begin{tabular}{|c|c|c|c|c|c|c|c|c|c|}
\hline & 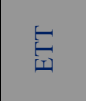 & $\underset{P}{?}$ & $\stackrel{\mathscr{\omega}}{\stackrel{1}{I}}$ & 3 & 茨 & \multicolumn{2}{|c|}{ Total } & $\begin{array}{c}\text { Priority } \\
\text { Vector } \\
(\mathrm{PV})\end{array}$ & $\begin{array}{l}\text { New } \\
\text { Vector } \\
(\mathrm{NV})\end{array}$ \\
\hline ETT & 0.455 & 0.600 & 0.294 & 0.360 & 0.366 & \multicolumn{2}{|c|}{2.075} & 0.415 & 2.283 \\
\hline ETU & 0.152 & 0.200 & 0.176 & 0.360 & 0.366 & \multicolumn{2}{|c|}{1.254} & 0.251 & 1.392 \\
\hline ETS & 0.091 & 0.067 & 0.059 & 0.040 & 0.024 & \multicolumn{2}{|c|}{0.281} & 0.056 & 0.295 \\
\hline LW & 0.152 & 0.067 & 0.176 & 0.120 & \begin{tabular}{|l|}
0.122 \\
\end{tabular} & \multicolumn{2}{|c|}{0.637} & 0.127 & 0.669 \\
\hline SF & 0.152 & 0.067 & 0.294 & 0.120 & 0.122 & \multirow{2}{*}{\multicolumn{2}{|c|}{0.754}} & 0.151 & 0.781 \\
\hline & & & & & & & & 1.000 & Total \\
\hline & 之 & 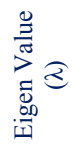 & 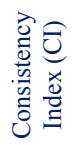 & 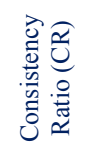 & $\frac{1}{2}$ & \multicolumn{2}{|c|}{ 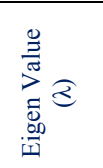 } & & \\
\hline ETT & 5.501 & 5.348 & 0.087 & 0.078 & & & & & \\
\hline ETU & 5.551 & & & & & & & & \\
\hline ETS & 5.259 & & & & & & & & \\
\hline LW & 5.251 & & & & & & & & \\
\hline SF & 5.176 & & & & & & & & \\
\hline \multirow[t]{3}{*}{ Total } & 26.739 & & & & & & & & \\
\hline & \multicolumn{3}{|c|}{ Synthesized Matrix } & & & & & & \\
\hline & 它 & $\frac{\sqrt{1}}{\sqrt{2}}$ & Total & $\begin{array}{c}\text { Priority } \\
\text { Vector } \\
(\mathrm{PV})\end{array}$ & $\begin{array}{c}\text { New } \\
\text { Vector } \\
(\mathrm{NV})\end{array}$ & $\frac{\text { z }}{\text { z }}$ & 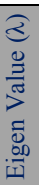 & 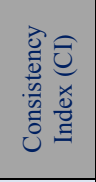 & 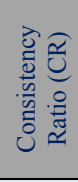 \\
\hline ST & 0.75 & 0.75 & 1.5 & 0.75 & 1.5 & 2 & 2 & 0 & $\mathbf{0}$ \\
\hline \multirow[t]{4}{*}{\begin{tabular}{|l|} 
NSE \\
\end{tabular}} & 0.25 & 0.25 & 0.5 & 0.25 & 0.5 & 2 & & & \\
\hline & & & & 1 & Total & 4 & & & \\
\hline & \multicolumn{3}{|c|}{ Synthesized matrix } & & & & & & \\
\hline & $\sum_{U}$ & $\sum_{j}^{e}$ & Total & $\begin{array}{c}\text { Priority } \\
\text { Vector } \\
(\mathrm{PV})\end{array}$ & $\begin{array}{c}\text { New } \\
\text { Vector } \\
(\mathrm{NV})\end{array}$ & $\sum_{z}^{z}$ & 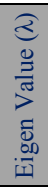 & 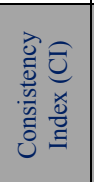 & 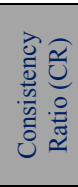 \\
\hline $\mathrm{CM}$ & 0.75 & 0.75 & 1.5 & 0.75 & 1.5 & 2 & 2 & 0 & $\mathbf{0}$ \\
\hline \multirow[t]{4}{*}{ CMP } & 0.25 & 0.25 & 0.5 & 0.25 & 0.5 & 2 & & & \\
\hline & & & & 1 & Total & 4 & & & \\
\hline & \multicolumn{3}{|c|}{ Synthesized matrix } & & & & & & \\
\hline & 号 & $\underset{|r|}{\ominus}$ & Total & $\begin{array}{c}\text { Priority } \\
\text { Vector } \\
\text { (PV) }\end{array}$ & $\begin{array}{c}\text { New } \\
\text { Vector } \\
(\mathrm{NV})\end{array}$ & $\sum_{\text {z }}^{\text {z }}$ & 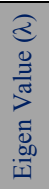 & 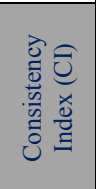 & 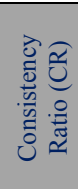 \\
\hline ETR & 0.75 & 0.75 & 1.5 & 0.75 & 1.5 & 2 & 2 & 0 & 0 \\
\hline ETD & 0.25 & 0.25 & 0.5 & 0.25 & 0.5 & 2 & & & \\
\hline & & & & 1 & Total & 4 & & & \\
\hline
\end{tabular}

TABLE V: ALl PRIORITY VECTORS FOR DFXS, SUB-DFXS AND DESIGN CONCEPTS

\begin{tabular}{|c|c|c|c|c|c|c|c|c|c|c|c|c|}
\hline & \multicolumn{12}{|c|}{ Priority vector } \\
\hline & \multicolumn{12}{|c|}{ Goal } \\
\hline \multirow[t]{2}{*}{ Criteria } & \multicolumn{5}{|c|}{$\mathbf{P}$} & \multicolumn{2}{|c|}{$\mathrm{s}$} & \multicolumn{2}{|c|}{ C } & E & \multicolumn{2}{|c|}{ M } \\
\hline & \multicolumn{5}{|c|}{0.456} & \multicolumn{2}{|c|}{0.191} & \multicolumn{2}{|c|}{0.099} & 0.191 & \multicolumn{2}{|c|}{0.062} \\
\hline \multirow[t]{2}{*}{ Sub-criteria } & ETT & ETU & ETS & LW & SF & ST & NSE & CM & CMP & & ETR & ETD \\
\hline & 0.415 & 0.251 & 0.056 & 0.127 & 0.151 & 0.750 & 0.250 & 0.750 & 0.250 & & 0.750 & 0.250 \\
\hline \multicolumn{13}{|l|}{ Aternatives } \\
\hline$D C-1$ & 0.175 & 0.215 & 0.093 & 0.170 & 0.112 & 0.144 & 0.189 & 0.126 & 0.124 & 0.120 & 0.262 & 0.195 \\
\hline DC-2 & 0.104 & 0.081 & 0.074 & 0.290 & 0.061 & 0.055 & 0.058 & 0.299 & 0.227 & 0.066 & 0.191 & 0.316 \\
\hline DC3 & 0.140 & 0.145 & 0.066 & 0.140 & 0.118 & 0.092 & 0.174 & 0.126 & 0.124 & 0.120 & 0.144 & 0.125 \\
\hline $\mathrm{DC}-4_{4}$ & 0.126 & 0.044 & 0.070 & 0.127 & 0.061 & 0.062 & 0.055 & 0.229 & 0.227 & 0.050 & 0.093 & 0.101 \\
\hline DC5 5 & 0.323 & 0.201 & 0.420 & 0.050 & 0.311 & 0.269 & 0.174 & 0.051 & 0.047 & 0.322 & 0.045 & 0.034 \\
\hline DC-6 & 0.080 & 0.162 & 0.074 & 0.167 & 0.084 & 0.147 & 0.174 & 0.169 & 0.182 & 0.100 & 0.198 & 0.165 \\
\hline $\mathrm{DC} 7 \mathrm{7}$ & 0.051 & 0.152 & 0.204 & 0.056 & 0.253 & 0.230 & 0.174 & 0.072 & 0.070 & 0.223 & 0.068 & 0.065 \\
\hline
\end{tabular}

TABLE VI: OVERALl PRIORITY VECTOR FOR THE DESIGN CONCEPTS WITH RESPECT TO THE DFXS

\begin{tabular}{|c|c|c|c|c|c|c|}
\hline & \multicolumn{5}{|c|}{ Priority vector } & \multirow{2}{*}{ O } \\
\cline { 1 - 4 } & $\mathbf{P}$ & $\mathbf{S}$ & $\mathbf{C}$ & $\mathbf{E}$ & $\mathbf{M}$ & \multirow{2}{*}{ Overall Priority } \\
\hline & $\mathbf{0 . 4 5 6}$ & $\mathbf{0 . 1 9 1}$ & $\mathbf{0 . 0 9 9}$ & $\mathbf{0 . 1 9 1}$ & $\mathbf{0 . 0 6 2}$ & \\
\hline & & & & & & \\
\hline DG-1 & 0.170 & 0.156 & 0.125 & 0.120 & 0.245 & 0.158 \\
\hline DC-2 & 0.114 & 0.056 & 0.228 & 0.066 & 0.222 & 0.111 \\
\hline DC-3 & 0.134 & 0.112 & 0.125 & 0.120 & 0.139 & 0.126 \\
\hline DC-4 & 0.093 & 0.060 & 0.228 & 0.050 & 0.095 & 0.092 \\
\hline DC-5 & 0.262 & 0.246 & 0.050 & 0.322 & 0.042 & 0.236 \\
\hline DC-6 & 0.112 & 0.154 & 0.173 & 0.100 & 0.190 & 0.129 \\
\hline DC-7 & 0.116 & 0.216 & 0.071 & 0.223 & 0.067 & 0.148 \\
\hline
\end{tabular}

In summary, Table VII shows that design concept number five (DC-5) has the highest value of 0.236. This is indicative that amongst all seven designs, design number five is favored. The lowest scoring design was design concept number four (DC-4). It is safe to say that design concept number four was tailored to cost and maintenance as opposed to concept number 5 which focused more on reliability. The results have demonstrated that the application of AHP in the conceptual design stage can help improve the quality of a product during the development process. AHP is a great tool which can be utilized as long as the consistency ratios are within margin $(\mathrm{CR}<0.10)$.

TABLE VII: RESUlt OF HOSPITAL BED CONCEPTUAL DESIGN SELECTION

\begin{tabular}{ccc}
\hline Ranking No. & Best Selection & Overall Priority \\
\hline 1 & DC-5 & $\mathbf{0 . 2 3 6}$ \\
2 & DC-1 & 0.158 \\
3 & DC-7 & 0.148 \\
4 & DC-6 & 0.129 \\
5 & DC-3 & 0.126 \\
6 & DC-2 & 0.111 \\
7 & DC-4 & 0.092 \\
\hline
\end{tabular}

\section{B. Finding the Best Hospital Bed Design Concept with Fuzzy Information}

Due to uncertainty and inability to provide the information on the compatibility between design concepts, we use fuzzy AHP and fuzzy conflict resolution technique to select the conceptual design. To begin, three experts' opinions are obtained with respect to DfX and Sub-DfX. Then, due to dilute the experts' opinions, we use two steps aggregation Max-Min delineated in Steps 1-2 \& 1-3. The aggregated linguistic values must be converted into fuzzy values based on the relationship between linguistic variables and triangular fuzzy number (TFN) determined in Table I.

The conversion of aggregated values from linguistic to 
fuzzy numbers in the pair-wise scale matrix can be viewed in Table VIII. Now, the value of fuzzy synthetic extent analysis can be applied to the fuzzy pair-wise scale matrix. equation (2) is used to compute the calculations. The calculations for the first two DfXs (Reliability and Safety) are performed below:

$$
\begin{gathered}
\text { Reliability }=(1+2 / 3+3 / 2+2 / 3+3 / 2) / 34.33=0.155 \\
(1+1+2+1+2) / 26.00=0.269 \\
(1+3 / 2+5 / 2+3 / 2+5 / 2) / 20.13=0.447 \\
\text { Safety }=(2 / 3+1+2 / 3+1+2 / 3) / 34.33=0.117 \\
(1+1+1+1+1) / 26.00=0.192
\end{gathered}
$$

\begin{tabular}{|c|c|c|c|c|c|c|c|c|}
\hline 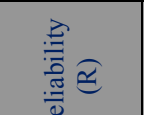 & 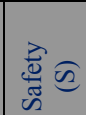 & 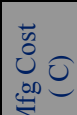 & 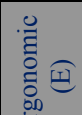 & 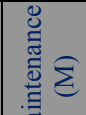 & 文 & \multicolumn{3}{|c|}{$\begin{array}{c}\text { Fuzzy Synthetic } \\
\text { Extent Values }\end{array}$} \\
\hline$(1,1,1)$ & \begin{tabular}{|c}
$(2 / 3,1$, \\
$3 / 2)$
\end{tabular} & $\begin{array}{c}(3 / 2,2 \\
, 5 / 2)\end{array}$ & $\begin{array}{c}(2 / 3,1, \\
3 / 2)\end{array}$ & \begin{tabular}{|c}
$(3 / 2,2$, \\
$5 / 2)$
\end{tabular} & $\begin{array}{l}\text { Reliabi } \\
\text { lity (R) }\end{array}$ & 0.155 & 0.269 & 0.447 \\
\hline$(2 / 3,1,3 / 2)$ & $(1,1,1)$ & $\begin{array}{c}(2 / 3,1 \\
, 3 / 2)\end{array}$ & $(1,1,1)$ & $\begin{array}{c}(2 / 3,1, \\
3 / 2)\end{array}$ & $\begin{array}{c}\text { Safety } \\
\text { (S) }\end{array}$ & 0.117 & 0.192 & 0.323 \\
\hline$(2 / 5,1 / 2,2 / 3)$ & $\begin{array}{c}(2 / 3,1, \\
3 / 2)\end{array}$ & $(1,1,1)$ & $\begin{array}{c}(2 / 3,1, \\
3 / 2)\end{array}$ & \begin{tabular}{|c}
$(2 / 3,1$, \\
$3 / 2)$
\end{tabular} & $\begin{array}{l}\text { Cost } \\
\text { ( C) }\end{array}$ & 0.099 & 0.173 & 0.306 \\
\hline$(2 / 3,1,3 / 2)$ & $(1,1,1)$ & $\begin{array}{c}(2 / 3,1 \\
, 3 / 2)\end{array}$ & $(1,1,1)$ & $\begin{array}{c}(2 / 3,1, \\
3 / 2)\end{array}$ & $\begin{array}{l}\text { Ergono } \\
\text { mic (E) }\end{array}$ & 0.117 & 0.192 & 0.323 \\
\hline$(2 / 5,1 / 2,2 / 3)$ & $\begin{array}{c}(2 / 3,1 \\
3 / 2)\end{array}$ & $\begin{array}{c}(2 / 3,1 \\
, 3 / 2)\end{array}$ & $\begin{array}{c}(2 / 3,1, \\
3 / 2)\end{array}$ & $(1,1,1)$ & $\begin{array}{c}\text { Mainte } \\
\text { nance } \\
(\mathrm{M})\end{array}$ & 0.099 & 0.173 & 0.306 \\
\hline $\begin{array}{r}\text { Total Sum o } \\
\text { PCM }\end{array}$ & I fuzzy & & & & & 0.586 & 1.00 & 1.705 \\
\hline $\mathrm{B} 1$ & 20.133 & & & & & & & \\
\hline $\mathrm{B} 2$ & 26.00 & & & & & & & \\
\hline B3 & 34.333 & & & & & & & \\
\hline
\end{tabular}$$
(3 / 2+1+3 / 2+1+3 / 2) / 20.13=0.323
$$

The same calculations are performed to the $S u b-D f X$ to

\begin{tabular}{|c|c|c|c|c|c|c|c|}
\hline & ETT & ETU & $\mathrm{SF}$ & $\mid S u b-D f R$ & \multicolumn{3}{|c|}{$\begin{array}{c}\text { Fuzzy Synthetic } \\
\text { Extent Values }\end{array}$} \\
\hline ETT & $(1,1,1)$ & $(2 / 3,1,3 / 2)$ & $(2 / 3,1,3 / 2)$ & ETT & 0.131 & 0.231 & 0.397 \\
\hline ETU & $(2 / 3,1,3 / 2)$ & $\overline{(1,1,1)}$ & \begin{tabular}{|l|}
$(2 / 3,1,3 / 2)$ \\
\end{tabular} & ETU & 0.107 & 0.192 & 0.348 \\
\hline ETS & $(2 / 5,1 / 2,2 / 3)$ & $(2 / 3,1,3 / 2)$ & $(2 / 5,1 / 2,2 / 3)$ & ETS & 0.091 & 0.154 & 0.265 \\
\hline LW & $(2 / 3,1,3 / 2)$ & $(2 / 3,1,3 / 2)$ & $(1,1,1)$ & LW & 0.117 & 0.192 & 0.323 \\
\hline SF & $(2 / 3,1,3 / 2)$ & $(2 / 3,1,3 / 2)$ & $(1,1,1)$ & $\mathrm{SF}$ & 0.141 & 0.231 & 0.373 \\
\hline \multicolumn{3}{|c|}{ Total Sum of fuzzy PCM } & & Total & 0.586 & 1.000 & 1.705 \\
\hline & B1 & 20.133 & & & & & \\
\hline & $\mathrm{B} 2$ & 26.000 & & & & & \\
\hline
\end{tabular}
obtain the fuzzy synthetic extent values (Refer to Table IX

\begin{tabular}{|c|c|c|c|c|c|c|}
\hline & B3 & 34.333 & & & & \\
\hline & ST & NSE & $|S u b-D f S|$ & \multicolumn{3}{|c|}{$\begin{array}{c}\text { Fuzzy Synthetic } \\
\text { Extent Values }\end{array}$} \\
\hline ST & $(1,1,1)$ & $(2 / 3,1,3 / 2)$ & ST & 0.333 & 0.5 & 0.75 \\
\hline \multirow[t]{7}{*}{ NSE } & $(2 / 3,1,3 / 2)$ & $\overline{(1,1,1)}$ & NSE & 0.333 & 0.50 & 0.75 \\
\hline & & & Total & 0.67 & 1.00 & 1.5 \\
\hline & \multicolumn{2}{|c|}{ Total Sum of fuzzy PCM } & & & & \\
\hline & B1 & 3.33 & & & & \\
\hline & B2 & 4.00 & & & & \\
\hline & B3 & 5.00 & & & & \\
\hline & CM & CMP & $|S u b-D f C|$ & \multicolumn{3}{|c|}{$\begin{array}{l}\text { Fuzzy Synthetic } \\
\text { Extent Values }\end{array}$} \\
\hline $\mathrm{CM}$ & $(1,1,1)$ & $(2 / 3,1,3 / 2)$ & $\mathrm{CM}$ & 0.3333 & 0.5 & 0.75 \\
\hline \multirow[t]{6}{*}{ CMP } & $(2 / 3,1,3 / 2)$ & $\overline{(1,1,1)}$ & CMP & 0.3333 & 0.50 & 0.75 \\
\hline & \multicolumn{2}{|c|}{ Total Sum of fuzzy PCM } & Total & 0.6667 & 1 & 1.5 \\
\hline & $\overline{\mathrm{B} 1}$ & 3.33 & & & & \\
\hline & B2 & 4.000 & & & & \\
\hline & B3 & 5.00 & & & & \\
\hline & ETR & ETD & Sub-DfE & \multicolumn{3}{|c|}{ Overall Weight } \\
\hline ETR & $(1,1,1)$ & $(2 / 3,1,3 / 2)$ & ETR & 0.333 & 0.5 & 0.75 \\
\hline \multirow[t]{5}{*}{ ETD } & $(2 / 3,1,3 / 2)$ & $(1,1,1)$ & ETD & 0.333 & 0.50 & 0.75 \\
\hline & \multicolumn{2}{|c|}{ Total Sum of fuzzy PCM } & Total & 0.667 & 1 & 1.5 \\
\hline & B1 & 3.33 & & & & \\
\hline & B2 & 4.000 & & & & \\
\hline & B3 & 5.00 & & & & \\
\hline
\end{tabular}
for more details).

TABLE IX: FUZZY SYNTHETIC EXTENT COMPUTATION FOR THE SUB-DFX
Thereafter, obtaining the synthetic extent values, the degree of possibility for each can now be calculated by using equation (4). Calculations are first performed to the $D f X$ followed by the Sub-DfXs. The degree of possibility for criteria $\mathrm{C} 1$ thru $\mathrm{C} 5$ (C1 being $D f R$ and $\mathrm{C} 5$ being $D f M$ ) can be viewed in Table $\mathrm{X}$. Calculations can be viewed below:

$\mathrm{C} 1>\mathrm{C} 2=(0.117-0.447) /((0.269-0.447)-(0.192-0.117))=1.303$

$\mathrm{C} 2>\mathrm{C} 1=(0.155-0.323) /((0.192-0.323)-(0.269-0.155))=0.685$

\begin{tabular}{|c|c|c|c|c|c|c|}
\hline$D f R$ & \multicolumn{2}{|c|}{ DfS } & \multicolumn{2}{|c|}{$D f C$} & DfE & $D f M$ \\
\hline \begin{tabular}{l|l|l}
$\mathrm{C} 1>\mathrm{C} 2$ & 1.303
\end{tabular} & $\mathrm{C} 2>\mathrm{C} 1$ & 0.685 & $\mathrm{C} 3>\mathrm{C} 1$ & 0.611 & $\mathrm{C} 4>\mathrm{C} 10.685$ & \begin{tabular}{|c|c|c|c|}
$\mathrm{C} 5$ & 0.611
\end{tabular} \\
\hline $\mathrm{C} 1>\mathrm{C} 3 \quad 1.382$ & $\mathrm{C} 2>\mathrm{C} 3$ & 1.094 & $\mathrm{C} 3>\mathrm{C} 2$ & 0.908 & \begin{tabular}{ll|l}
$\mathrm{C} 4>\mathrm{C} 2$ & 1.000
\end{tabular} & $\begin{array}{lll}\mathrm{C} 5 & >\mathrm{C} 2 & 0.908\end{array}$ \\
\hline $\mathrm{C} 1>\mathrm{C} 4 \mid 1.303$ & $\mathrm{C} 2>\mathrm{C} 4$ & 1.000 & $\mathrm{C} 3>\mathrm{C} 4$ & 0.908 & C4 $>$ C3 1.094 & $\begin{array}{lll}\mathrm{C} 5 & >\mathrm{C} 3 & 1.000\end{array}$ \\
\hline \begin{tabular}{ll|l|}
$\mathrm{C} 1>\mathrm{C} 5$ & 1.382 \\
\end{tabular} & $\mathrm{C} 2>\mathrm{C} 5$ & 1.094 & $\mathrm{C} 3>\mathrm{C} 5$ & 1.000 & \begin{tabular}{|l|l|}
$\mathrm{C} 4>\mathrm{C} 5$ & 1.094 \\
\end{tabular} & \begin{tabular}{|l|l|l|} 
C5 & 0.908 \\
\end{tabular} \\
\hline
\end{tabular}

$\mathrm{C} 3>\mathrm{C} 1=(0.155-0.306) /((0.173-0.306)-(0.269-0.155))=0.611$

$\mathrm{C} 4>\mathrm{C} 1=(0.155-0.323) /((0.192-0.323)-(0.269-0.155))=0.685$

$\mathrm{C} 5>\mathrm{C} 1=(0.155-0.306) /((0.173-0.306)-(0.269-0.155))=0.611$

TABLE X: DEgREe OF POSSIBILITY FOR THE $D F X$

\begin{tabular}{|c|c|c|c|c|}
\hline R-SC1 & R-SC2 & R-SC3 & R-SC4 & R-s \\
\hline \begin{tabular}{l|l}
$\mathrm{R}-\mathrm{SC} 1>\mathrm{R}-\mathrm{SC} 2$ & 1.153 \\
\end{tabular} & \begin{tabular}{|l|l|}
$\mathrm{R}-\mathrm{SC} 2>\mathrm{R}-\mathrm{SC} 1$ & 0.849 \\
\end{tabular} & \begin{tabular}{|l|l|l|l|} 
R-SC $3>\mathrm{R}-\mathrm{SC} 1$ & 0.635 \\
\end{tabular} & \begin{tabular}{|l|l|l|l} 
R-SC $>$ R-SC 1 & 0.833 \\
\end{tabular} & $\overline{C 11.000}$ \\
\hline \begin{tabular}{l|l|l|l|}
$\mathrm{R}-\mathrm{SC} 1>\mathrm{R}-\mathrm{SC} 3$ & 1.336 \\
\end{tabular} & R-SC2>R-SC3 1.176 & \begin{tabular}{|l|l|} 
R-SC3>R-SC2 & 0.804 \\
\end{tabular} & \begin{tabular}{|l|l|}
$\mathrm{R}-\mathrm{SC} 4>\mathrm{R}-\mathrm{SC} 2$ & 1.000 \\
\end{tabular} & 1.169 \\
\hline \begin{tabular}{l|l} 
R-SC1>R-SC4 & 1.159 \\
\end{tabular} & \begin{tabular}{|l|l|} 
R-SC2>R-SC4 & 1.000 \\
\end{tabular} & \begin{tabular}{|l|l|} 
R-SC3>R-SC4 & 0.794 \\
\end{tabular} & \begin{tabular}{|l|l|} 
R-SC4>R-SC3 & 1.199 \\
\end{tabular} & R-SC5>R-SC3 1.376 \\
\hline \begin{tabular}{l|l}
$\mathrm{R}-\mathrm{SC} 1>\mathrm{R}-\mathrm{SC} 5$ & 1.000 \\
\end{tabular} & \begin{tabular}{|l|l|l|} 
R-SC2>R-SC5 & 1.000 \\
\end{tabular} & \begin{tabular}{|l|l|} 
R-SC3>R-SC5 & 0.617 \\
\end{tabular} & \begin{tabular}{|l|l|}
$\mathrm{R}-\mathrm{SC} 4>\mathrm{R}-\mathrm{SC} 5$ & 0.826 \\
\end{tabular} & R-SC5>R-SC4 1.177 \\
\hline
\end{tabular}

The results for the $S u b-D f R$ under design for reliability $(D f R)$ can be expressed by using R-SC1 thru R-SC5 (R-SC1 being Easy to Transfer and R-SC5 being Strong Frame), and the results can be viewed in Table XI.
The results for the design for safety sub-criteria under safety criteria can be expressed by using S-SC1 thru S-SC5 (S-SC1 being stability), and the results can be viewed in Table XII.

The results for the $S u b-D f C$ under design for manufacturing cost can be expressed by using C-SC1 thru C-SC5 (C-SC1 being cost of material), and the results can be viewed in Table XIII.

The results for the sub-criteria under maintenance criteria can be expressed by using M-SC1 thru M-SC5 (M-SC1 easy to repair), and the results can be viewed in Table XIV.

TABLE XII: DEGREE OF POSSIBILITY FOR THE SUB-DFX SAFETY
\begin{tabular}{llll}
\hline S-SC1 & S-SC2 & \\
\hline S-SC1>S-SC2 & 1 & S-SC2 $>$ S-SC1 & 1 \\
\hline
\end{tabular}

TABLE XIII: DEGREE OF POSSIBILITY FOR THE SUB-DFC

\begin{tabular}{llll}
\hline C-SC1 & C-SC2 & \\
\hline C-SC1 $>$ C-SC2 & 1 & C-SC2>C-SC1 & 1 \\
\hline
\end{tabular}

TABLE XIV: DEGREE OF POSSIBILITY FOR THE SUB-DFM

\begin{tabular}{llll}
\hline M-SC1 & \multicolumn{3}{l}{ M-SC2 } \\
\hline M-SC1>M-SC2 & 1 & M-SC2>M-SC1 & 1 \\
\hline
\end{tabular}


Next step is calculating the weight vector (W') by using Equation (7).The calculations for the weight vector for the criteria are shown below:

$$
\begin{aligned}
& \text { d' }(\mathrm{C} 1)=\mathrm{V}(\mathrm{C} 1 \geq \mathrm{C} 2, \mathrm{C} 3, \mathrm{C} 4, \mathrm{C} 5)=\min (1,1,1,1)=1 \\
& \text { d' }(\mathrm{C} 2)=\mathrm{V}(\mathrm{C} 2 \geq \mathrm{C} 1, \mathrm{C} 3, \mathrm{C} 4, \mathrm{C} 5)=\min (0.685,1,1,1)=0.685 \\
& \mathrm{~d}^{\prime}(\mathrm{C} 3)=\mathrm{V} \quad(\mathrm{C} 3 \geq \mathrm{C} 1, \mathrm{C} 2, \mathrm{C} 4, \mathrm{C} 5)=\mathrm{min} \\
& (0.611,0.908,0.908,1)=0.611 \\
& \text { d' }(\mathrm{C} 4)=\mathrm{V}(\mathrm{C} 4 \geq \mathrm{C} 1, \mathrm{C} 2, \mathrm{C} 3, \mathrm{C} 5)=\min (0.685,1,1,1)=0.685 \\
& \text { d'(C5) }=\mathrm{V}(\mathrm{C} 5 \geq \mathrm{C} 1, \mathrm{C} 2, \mathrm{C} 3, \mathrm{C} 4)=\min (0.611,0.908,1, \\
& 0.908)=0.611
\end{aligned}
$$

Therefore, $\mathrm{W}^{\prime}=(1,0.685,0.611,0.685,0.611)$

The calculations for the weight vector (W') for the Sub- $D f X s$ pertaining to $D f R$ are shown below:

d' $(\mathrm{R}-\mathrm{SC} 1)=V(\mathrm{R}-\mathrm{SC} 1 \geq \mathrm{R}-\mathrm{SC} 2, \mathrm{R}-\mathrm{SC} 3, \mathrm{R}-\mathrm{SC} 4, \mathrm{R}-\mathrm{SC}$ $5)=\min (1,1,1,1)=1$

$\mathrm{d}^{\prime}(\mathrm{R}-\mathrm{SC} 2)=V(\mathrm{R}-\mathrm{SC} 2 \geq \mathrm{R}-\mathrm{SC} 1, \mathrm{R}-\mathrm{SC} 3, \mathrm{R}-\mathrm{SC} 4, \mathrm{R}-\mathrm{SC}$

$5)=\min (0.849,1,1,1)=0.849$

d' $(\mathrm{R}-\mathrm{SC} 3)=V(\mathrm{R}-\mathrm{SC} 3 \geq \mathrm{R}-\mathrm{SC} 1, \mathrm{R}-\mathrm{SC} 2, \mathrm{R}-\mathrm{SC} 4, \mathrm{R}-\mathrm{SC}$

$5)=\min (0.635,0.804,0.794,0.617)=0.617$

d'(R-SC 4) = V(R-SC $4 \geq$ R-SC 1, R-SC 2, R-SC 3, R-SC

$5)=\min (0.833,1,1,0.826)=0.826$

d'(R-SC 5)= V(R-SC $5 \geq$ R-SC 1, R-SC 2, R-SC 3, R-SC

$4)=\min (1,1,1,1)=1$

Therefore, $\mathrm{W}^{\prime}=(1,0.849,0.617,0.826,1)$

The calculations for the weight vector (W') for the

Sub-DfS pertaining to safety are shown below:

$\mathrm{d}^{\prime}(\mathrm{S}-\mathrm{SC} 1)=V(\mathrm{~S}-\mathrm{SC} 1 \geq \mathrm{S}-\mathrm{SC} 2, \mathrm{~S}-\mathrm{SC} 3, \mathrm{~S}-\mathrm{SC} 4, \mathrm{~S}-\mathrm{SC} 5)=$ $\min (1,1)=1$

$\mathrm{d}^{\prime}(\mathrm{S}-\mathrm{SC} 2)=V(\mathrm{~S}-\mathrm{SC} 2 \geq \mathrm{S}-\mathrm{SC} 1, \mathrm{~S}-\mathrm{SC} 3, \mathrm{~S}-\mathrm{SC} 4, \mathrm{~S}-\mathrm{SC} 5)=$ $\min (1,1)=1$

Therefore, $\mathrm{W}^{\prime}=(1,1)$

The calculations for the weight vector (W') for the

$S u b-D f C$ pertaining to cost are shown below:

$\mathrm{d}^{\prime}(\mathrm{C}-\mathrm{SC} 1)=V(\mathrm{C}-\mathrm{SC} 1 \geq \mathrm{C}-\mathrm{SC} 2, \mathrm{C}-\mathrm{SC} 3, \mathrm{C}-\mathrm{SC} 4, \mathrm{C}-\mathrm{SC}$

$5)=\min (1,1)=1$

$\mathrm{d}^{\prime}(\mathrm{C}-\mathrm{SC} 2)=V(\mathrm{C}-\mathrm{SC} 2 \geq \mathrm{C}-\mathrm{SC} 1, \mathrm{C}-\mathrm{SC} 3, \mathrm{C}-\mathrm{SC} 4, \mathrm{C}-\mathrm{SC}$

$5)=\min (1,1)=1$

Therefore, $\mathrm{W}^{\prime}=(1,1)$

The calculations for the weight vector (W') for the

Sub-DfM pertaining to maintenance are shown below:

d'(M-SC 1) $=\mathrm{V}(\mathrm{M}-\mathrm{SC} 1 \geq \mathrm{M}-\mathrm{SC} 2, \mathrm{M}-\mathrm{SC} 3, \mathrm{M}-\mathrm{SC} 4$, $\mathrm{M}-\mathrm{SC} 5)=\min (1,1)=1$

$\mathrm{d}^{\prime}(\mathrm{M}-\mathrm{SC} 2)=\mathrm{V}(\mathrm{M}-\mathrm{SC} 2 \geq \mathrm{M}-\mathrm{SC} 1, \mathrm{M}-\mathrm{SC} 3, \mathrm{M}-\mathrm{SC} 4$, $\mathrm{M}-\mathrm{SC} 5)=\min (1,1)=1$

Therefore, $\mathrm{W}^{\prime}=(1,1)$

Now that the weights vectors have been obtain for both

$D f X$ and $\operatorname{Sub}-D f X$, they can be added accordingly (See Table

$\mathrm{XV}$ for results) as shown below:

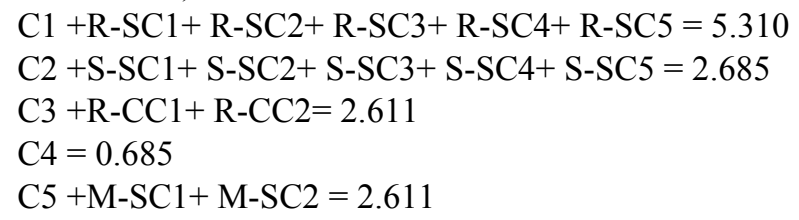

TABLE XV: WEIGHT VECTORS FOR DFX AND SUB-DFX

\begin{tabular}{lll}
$\mathrm{W}^{\prime}$ & $\mathrm{d}^{\prime}(\mathrm{C} 1$ \& R-SC) & 5.310 \\
$\mathrm{~W}^{\prime}$ & $\mathrm{d}^{\prime}(\mathrm{C} 2$ \& S-SC) & 2.685 \\
$\mathrm{~W}^{\prime}$ & $\mathrm{d}^{\prime}(\mathrm{C} 3$ \& C-SC) & 2.611 \\
$\mathrm{~W}^{\prime}$ & $\mathrm{d}^{\prime}(\mathrm{C} 4$ \& E-SC) & 0.685 \\
$\mathrm{~W}^{\prime}$ & $\mathrm{d}^{\prime}(\mathrm{C} 5$ \& M-SC) & 2.611 \\
\hline
\end{tabular}

Via normalizing the weight vectors using equation (8), the normalize weight vectors can be viewed in Table XVI.

\begin{tabular}{ccc}
\multicolumn{3}{c}{ TABLE XVI: NORMALIZED WEIGHT VECTORS } \\
\hline W & d' (C1 \& R-SC) & $\mathbf{0 . 3 8 2}$ \\
W & d' (C2 \& S-SC) & 0.193 \\
W & d' (C3 \& C-SC) & 0.188 \\
W & d' (C4 \& E-SC) & 0.049 \\
W & d' (C5 \& M-SC) & 0.188 \\
\hline
\end{tabular}

\section{CONCLUSION}

A structured conceptual design selection model based on fuzzy analytic hierarchy process (FAHP) and fuzzy conflict resolution technique to express the comparative judgments of designers was developed. The model was applied to the hospital bed designs with crisp and fuzzy information. FAHP has determined that the best design concept is the design which is tailored to reliability and safety. The importance of reliability was weighted at $38.2 \%$, followed by safety with $19.3 \%$. Both AHP and Fuzzy AHP have determined that these two features built in the conceptual design will constitute a marketable and profitable product. There are a number of reasons AHP and Fuzzy AHP producing similar results. First, the consistency ratios were promising to begin with. The paper emphasized the selection of reliability over all other $D f X$ s and was not as interested in much else. Based on that selection, the judgments were accurate to begin with therefore inconsistencies were not apparent. In the end, this study proves that AHP and FAHP are good methods but FAHP along with conflict resolution technique eliminates inconsistencies due to personal feelings or judgments. Applied in different case scenarios, where more than one $D f X s$ is emphasized, inconsistencies in pair-wise is introduced and factored throughout the model. Without applying FAHP, the overlooked inconsistencies can lead to selecting the incorrect design and those results could potentially mean failure to meet demands and could end in loss of profit. Unless numerical values are present, or straight forward $D f X s$ is chosen, FAHP should be regarded as the method of choice.

\section{ACKNOWLEDGMENT}

Authors would like to express their sincere appreciation to anonymous referees for their valuable comments that enhanced the quality of the paper.

\section{REFERENCES}

[1] G. Avigad, E. Eisenstadt and B. Shnits, "Supporting the selection of robust engineering concepts under suppliers related uncertainties", Journal of Engineering Design, vol.22, no.8, pp.543-563, 2011.

[2] U. Cebeci, "Fuzzy AHP-based decision support system for selecting ERP systems in textile industry by using balanced scorecard", Expert Systems With Applications, vol.36, no.5, pp.8900-8909, 2009.

[3] D.Y. Chang, "Applications of the extent analysis method on fuzzy AHP”, European Journal of Operational Research, vol.95, no.3, pp.649-655, 1996.

[4] Y.T. Chong, C.H. Chen and K.F Leong, "A heuristic-based approach to conceptual design", Research in Engineering Design, vol.20, pp.97-116, 2009.

[5] A.Febransyah \& J.B. Utarja, "A fuzzy-based decision making approach for product concept selection", Jurnal Teknik Industri, vol.6, no.1, pp.25-30, 2004. 
[6] A.H. Hu, C.W. Hsu, T.C. Kuo and Wu W.C., "Risk evaluation of green components to hazardous substance using FMEA and FAHP", Expert Systems, vol.36 no.3-Part 2, pp.7142-7147, 2009.

[7] D. Kim \& P. Xirouchakis, "CO ${ }^{2} \mathrm{DE}$ : A decision support system for collaborative design", Journal of Engineering Design, vol.21, no.1, pp.31-48, 2010.

[8] A.M. King \& S. Sivaloganathan, "Development of a methodology for concept selection in flexible design strategies", Journal of Engineering Design, vol.10, no.4, pp.329-349, 1999.

[9] K. Kurakawa, "A scenario-driven conceptual design information model and its formation", Research in Engineering Design, vol.15, pp.122-137, 2004.

[10] G.F. Milanka, "Multicriteria optimization in a fuzzy environment: The fuzzy analytic hierarchy process", Yugoslav Journal of Operations Research, vol.20, no.1, pp.71-85, 2010.

[11] M. Modarres, S. Sadi-Nezhad, and F. Arabi, "Fuzzy analytical hierarchy process using preference ratio: A case study for selecting management short course in a business school", International Journal of Industrial Engineering Computations, vol.1, pp.173-184, 2010.

[12] R.L. Nagel, R. Hutcheson, D.A. McAdams and R. Stone, "Process and event modelling for conceptual design", Journal of Engineering Design, vol.22, no.3, pp1.45-164, 2011.

[13] T.L. Saaty, "Decision making with dependence and feedback: The analytic network process", Pittsburgh: RWS Publications. 1996.

[14] T.L. Saaty, "A scaling for priorities in hierarchical structures", Journal of Mathematical Psychology, vol.15, no.3, pp.234-281, 1980.

[15] Y.C. Tang \& M.J. Beynon, "Application and development of the fuzzy analytic hierarchy process within a capital investment study", Journal of Economics and Management, vol.1, no.2, pp.207-230, 2005.

[16] E. Tolga, M.L. Demircan and C. Kahraman, "Operating system selection using fuzzy replacement analysis and analytic hierarchy process", International Journal of Production Economics, vol.97, pp.89-117, 2005.

[17] J. Wang, "Improved engineering design concept selection using fuzzy sets", International Journal of Computer Integrated Manufacturing, vol.15, no.1, pp.18-27, 2002.

[18] L. Wang, W. Shen, H.Xie, J. Neelamkavil and A. Pardasani, "Collaborative conceptual design - State of the art and future trends", Computer Aided Design, vol.34, pp.981-996, 2002.

[19] Z.Y. Yang, Y.H. Chen and W.S. Sze, "Using AHP and fuzzy sets to determine the build orientation in layer-based machining",
International Journal Computer Integrated Manufacturing, vol.16, no.6, pp.398-408. 2003.

[20] C.S. Yu, "A GP-AHP method for solving group decision-making fuzzy AHP problems", Computers \& Operations Research, vol.29, pp.1969-2001, 2002.

[21] L.A. Zadeh, "Fuzzy sets. Information and Control”, vol.8, pp.338-353. (1965).

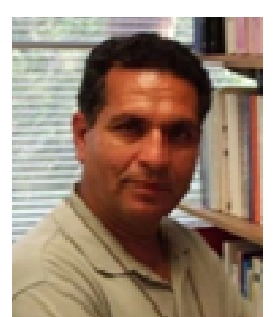

Ahmad Sarfaraz is a Professor of Engi-neering Management at Department of Manufacturing System Engineering and Management, California State University, Northridge. His research interests are in Operation Research, AHP, Facilities Layout and Location, and Economic Analysis. He is author or co-author of numerous publications and consults in Facilities Planning and Lean Manufacturing, System Analysis, Expert Sys-tems, and Operations Modeling. He also received Engineer's Council Merit Award for the year 2002. He is the director of MSEM Solutions Center and Facilities-VEDC community service learning

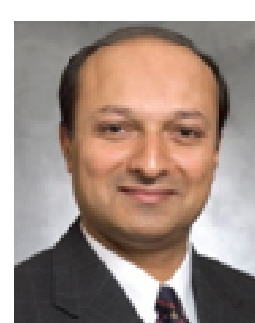

Kouroush Jenab, Senior Member of IEEE, received the B.Sc. degree from the IE Department at Isfahan University of Technology (1989), the M.Sc. degree from the IE Department at Tehran Polytechnic (1992), and the Ph.D. degree from the Department of Mechanical Engineering at the University of Ottawa (2005). He served as a senior engi-neer/manager in auto, and high-tech industries for 18 years. He joined National Research Council Canada as a research officer where he participated in several international research projects. In 2006, he joined the Department of Mechanical and Industrial Engineering at Ryerson University, Toronto as assistant professor. Currently, Dr. Jenab is a Visiting Professor in Department of I.E. at IUST and Centre of Excellence in I.E.. He is also Education Chair of Society of Reliability Engineering (SRE)-Ottawa Chapter. He has published several papers in international scientific journals based on his experiences in industries. 